\title{
A Crítica como Vestígio de Recepção: The West Wing e o Real Histórico
}

\author{
Regina Gomes \\ Doutora em Ciências da Comunicação \\ pela Universidade Nova de Lisboa, \\ professora no Curso de Comunicação \\ Social e no Programa de Pós- \\ Graduação em Comunicação e Cultura \\ Contemporâneas da Universidade \\ Federal da Bahia onde também é \\ Coordenadora do Grupo de Pesquisa \\ Recepção e Crítica da Imagem. Tem \\ experiência na área de Comunicação \\ com ênfase em Análise e Crítica de \\ Cinema e Audiovisual. \\ E-mail: reginagomesbr@gmail.com
}

Resumo: Este trabalho visa refletir sobre a crítica enquanto elemento histórico que opera como um registro de recepção de obras audiovisuais. Defendemos que estes textos avaliativos publicados em jornais, revistas, impressos ou eletrônicos, constituem-se como vestígios de uma experiência receptiva que deixa uma marca inscrita na história das obras audiovisuais. Além disso, tomaremos como objeto de estudo algumas críticas direcionadas à ficção televisiva americana The West Wing.

\section{Palavras-chave: Recepção; Crítica; The West Wing}

Abstract: This paper aims to reflect on the criticism one as historical element that operates as a record reception of audiovisual works. We defend that these evaluative texts published in newspapers, magazines, printed or electronic, consist as vestiges of a receptive experience that leaves a mark inscribed in the history of the audiovisual works. Moreover, we will take as the object of study, some reviews for American TV show The West Wing.

Keywords: Reception; Criticism; The West Wing.

\section{Introdução}

De um modo geral, os estudos de recepção ligados ao audiovisual partem de perspectivas já relativamente discutidas no campo, prova disso foram as primeiras pesquisas cinematográficas, no início do século passado, empreendidas por Jean Mitry e sua fenomenologia da percepção e, mais tarde, a preocupação dos estruturalistas franceses em pensar o filme como um dispositivo ideológico. Recentemente, o conceito de espectatorialidade tem motivado importantes discussões que enfatizam a passagem do "público ao espectador". Da mesma forma, entre as matrizes das teorias da comunicação até os mais recentes estudos culturais, a preocupação com as audiências da televisão e com a atividade (ou inatividade) do telespectador, tem motivado investigações que ajudaram a moldar o campo que, embora ainda em construção, passou a ter a rubrica de estudos de recepção.

Entretanto, poucos projetos têm se dedicado a investigar o caráter histórico desses processos de recepção, apesar da existência de fontes e materiais ricos em registros de experiências receptivas e prontos para serem analisados. A nossa proposta aqui será a de considerar a crítica de produtos audiovisuais, efetivamente os registros escritos, como uma instância de recepção. 
Faremos, inicialmente, uma breve revisão de ideias de correntes teóricas particularmente a Estética da Recepção e os Estudos Históricos de Recepção - a fim de levar novos horizontes de problemas ao campo e, com isso, contribuir para o debate. Posteriormente, abrigaremos uma análise das críticas dirigidas à série televisiva The West Wing (1999-2006) produzida pela emissora NBC e roteirizada pelo escritor Aaron Sorkin.

\title{
A estética da recepção e a crítica
}

A estética da recepção, corrente nascida na Escola de Konstanz, Alemanha que tem entre seus principais expoentes Hans Robert Jauss (1979;1994; 2002) e Wolfgang Iser (1979) - já na década de 1970 compreendia os textos de crítica literária como integrantes da recepção das obras e como testemunhos dos sentidos conferidos à essas mesmas obras ao longo do tempo. Deslocando o foco de atenção do texto para o receptor, a estética da recepção valorizava a experiência estética como condição ativa para as atividades de fruição e interpretação do texto literário.

Vale mencionar que enquanto Jauss (1979) demarcou o alcance de sua pesquisa para a recepção da obra no seu horizonte de tempo, Iser (1979) preocuparase mais com o efeito que o texto causa no leitor. Em decorrência, para Jauss, qualquer movimento de análise de recepção de uma obra não deve desconsiderar as condições históricas uma vez que recepção se estende nos tecidos sociais. Jauss (1994: 57) refere que é preciso superar "o abismo entre literatura e história, entre o conhecimento estético e o histórico", e fugir da mera descrição linear dos fatos. E se pensarmos na história dos produtos audiovisuais esta superação também se faz urgente. A história do audiovisual não é apenas a história quantitativa de suas obras mais significativas, mas a compreensão de como os espectadores têm recebido essas obras ao longo do tempo.

E se a historicidade da recepção parece ser algo incontestável, Jauss argumenta que:

\begin{abstract}
A história da literatura é um processo de recepção e produção estética que se realiza na atualização dos textos literários por parte do leitor que os recebe, do escritor, que se faz novamente produtor, e do crítico, que sobre eles reflete (JAUSS, 1994: 25).
\end{abstract}

Não por acaso, a estética da recepção chama a atenção para a instância da crítica. A importância do crítico e de seus escritos como parte constituinte do processo de atualização de textos artísticos revela que a análise dos atos de leitura e de fruição inscritos nas críticas é não apenas necessária, como fundamental para aquilo que chamamos de estudos de recepção nos media.

Os juízos acumulados da crítica, aliado a outros juízos (dos leitores, espectadores, professores), formam uma camada de sentido que é historicamente atualizada em sua recepção e traduzem um conjunto de atos de interpretação e fruição que se revigoram no tempo.

Por fim, acreditamos ser importante o exame de condicionantes históricos e estéticos que levaram a uma boa ou má acolhida de certos produtos audiovisuais, inseridos em seu horizonte de expectativas. Além disso, a interpretação - ou o registro desta leitura interpretativa nas críticas - é sempre marcada pelo contexto que, muitas vezes, a condiciona de tal forma a ponto de ser impossível separar a partilha entre a obra e seu entorno e encontrar sentido apenas no contorno circunstanciado do texto. 


\section{Para além dos limites dos textos audiovisuais}

As investigações de Janet Staiger (1992; 2000; 2005) e seus "estudos históricos de recepção nos media" tecem fortes aproximações com a valorização do horizonte histórico-contextual na instância de recepção das obras defendida pela estética da recepção e têm contribuído para avigorar a ideia da crítica como marca de recepção.

Filiada à uma tradição historiográfica, Staiger faz mais do que inserir seus estudos num simples retorno à história do cinema e expande seus objetos de trabalho para um lugar de equilíbrio entre texto e contexto. Por trás desta perspectiva, vê-se claramente a crítica da autora, assim como a de Jauss, ao sentido imanente do texto e a contestação da retirada da recepção de seu lugar na história. Staiger (1992) afirma que é necessário fazer uma compreensão histórica das atividades interpretativas, mais do que uma interpretação de textos. Traça assim, um limite entre os estudos de textos e os estudos de recepção, as "análises textuais" limitam-se à busca do significado oculto gerando interpretações decorrentes de um exame interno às obras, já os estudos de recepção objetivam refletir sobre os atos de leitura e porque estes atos são conformados historicamente. Staiger de certo modo questiona a ortodoxia dos estudos históricos tradicionais do cinema que eclipsavam o interesse mais analítico das investigações.

Convém lembrar que Staiger (2000) devota mais atenção aos estudos de recepção no cinema, mas em Perverse Spectators admite que "embora eu não trabalhe com estudos televisivos, em geral eu acho que muito do que apresento aqui é aplicável

${ }^{1}$ No original: "Although I do no studies of television, on the whole I think much of I present here is applicable to TV".

\footnotetext{
${ }^{2}$ Somente em sua primeira temporada The West Wing conquistou nove prêmios Emmy, o que a levou ao patamar da mais premiada série em temporada de estreia na TV americana.
} à TV"1 (STAIGER, 2000: 6). Com efeito, a aproximação com os estudos televisivos é salutar e abre uma janela para as investigações sobre os métodos interpretativos de espectadores de TV.

A autora parte de documentos escritos como críticas, boletins, contratos legais, programas de exposições, manuais, textos jornalísticos, comentários de fãs e até cartões escolares de pontuação para classificação de filmes, a fim de investigar como os fatores contextuais têm peso significativo nas experiências dos espectadores ao assistirem filmes e TV. Além disso, esses documentos são excelentes fontes para reconstruir estratégias interpretativas e respostas do público em um determinado horizonte histórico.

A proposta de considerar a pesquisa empírica e a busca de evidências em fontes remetem ao diálogo metodológico de Staiger não somente com a história, mas igualmente com a sociologia evidenciando e ao mesmo tempo ampliando o domínio sobre modos de recepção dos mídia, pois as fontes são territórios privilegiados de associações contextuais que podem fornecer respostas e apoio tangível à especulação teórica e à compreensão da recepção de produtos audiovisuais.

\section{As críticas à The West Wing}

The West Wing (1999-2006) é uma série televisiva produzida pela emissora norteamericana NBC e escrita pelo conceituado roteirista Aaron Sorkin. Durante as suas sete temporadas, a ficção acumulou prêmios ${ }^{2}$ e fãs, suscitou críticas e despertou polêmicas nos meios jornalísticos e acadêmicos de vários países. Exibida no Brasil pelo Warner Channel, GNT e SBT, incitou a produção de textos em publicações como o jornal Folha de São Paulo e na revista de cinema Contracampo. Boa parte da polêmica motivada por The West Wing associa-se ao seu caráter políticoideológico e à capacidade do roteirista em levantar discussões sobre temas atuais.

Classificada como sendo do gênero Workplace Drama, The West Wing teve como foco o universo de trabalho dos assessores de um fictício presidente americano, 
localizado nos escritórios da Ala Oeste da Casa Branca. A equipe de assessores era formada basicamente pelos personagens Leo McGarry (John Spencer), chefe de gabinete e amigo do presidente liberal Jed Bartlet (Martin Sheen), Josh Lyman (Bradley Whitford), assistente de Estado Maior e importante estrategista político, Toby Ziegler (Richard Schiff), chefe de comunicações, Sam Seaborn (Rob Lowe), redator de textos e discursos da presidência e por CJ Cregg (Allison Janney), assessora de imprensa e porta-voz da Casa Branca.

Misturando drama e humor, a série descreve com competência o mundo macro da política contemporânea e expõe o modo de funcionamento das instituições democráticas, apresentando personagens idealizados, mas imperfeitos em suas ações e em seus confrontos íntimos. É provável que a habilidade de Aaron Sorkin de conjugar realisticamente dramas geopolíticos atuais com a miudeza dos tormentos particulares daqueles que compõem o mundo decisório da Casa Branca, tenha reforçado o pacto com público ao despertar o interesse pelo tema, e o prestígio angariado pela crítica.

Entretanto, o fato da série ter gerado um grande debate público foi aqui importante para a escolha de nosso objeto de estudo não somente pela riqueza de material produzido, mas, sobretudo, pela possibilidade de sua repercussão temática ter desviado a atenção da crítica de uma avaliação que considerasse os aspectos estéticos expressivos da ficção e certamente, de como as configurações sociais e políticas foram favoráveis a este tipo de recepção.

\section{Situando a série e a crítica}

Jauss (1994: 28) afirma que: "a obra que surge não se apresenta como novidade absoluta num espaço vazio", na verdade, "ela desperta a lembrança do já lido" e "antecipa um horizonte geral da compreensão vinculado". The West Wing fora concebida por Sorkin em 1997, utilizando ideias remanescentes do roteiro de Meu querido presidente, comédia dirigida por Rob Reiner em 1995. Apresentou o projeto a John Wells, grande produtor da NBC, mas a rede receava que os fatos por trás do recente escândalo "Mônica Lewinsky x Bill Clinton" tivessem afetado a crença da audiência por dramas políticos "sérios". Tempos depois, quando outras redes demonstraram interesse pela ficção, a NBC decidiu apostar no projeto ambicioso de Sorkin. A série estreou no outono de 1999 e a crítica já reconhecia os traços familiares deste drama político que retratava o cotidiano do presidente e de sua equipe de profissionais. Esses traços familiares eram bastante legíveis no contexto experienciado, predispondo, ao contrário do que previu a NBC, o público a acolhê-la de modo entusiasmado, mas não sem controvérsias.

As indicações de familiaridade vinham de outras produções como Hill Street Blues, Law and Order, ER e sobretudo Sports Nights, cuja ações dramáticas também desenvolvem-se em ambiente de trabalho bem como as relações pessoais misturadas com as profissionais. Não por acaso, Sports Nights conta com a participação de Sorkin e de seu fiel colaborador, Thomas Schlamme, criador da identidade visual de The West Wing e das ágeis tomadas de acompanhamento

${ }^{3}$ Para uma análise dos aspectos estéticos de The West Wing ver: GOMES, Regina (2011). chamadas de Walk and Talk ${ }^{3}$. Além disso, a discussão sobre o poder político e as intrigas palacianas de Washington não eram novidades para a audiência americana que não estranhava ver o presidente confrontado com os casos de corrupção como em Washington Behind Closed Doors (1977), microssérie sobre a corrupção política na instituição mais sagrada dos Estados Unidos: o congresso americano.

Tous (2010) defende ainda que a série conjuga elementos de várias eras televisivas e particularmente recupera as antigas funções de informar, educar e entreter da denominada "era paleotelevisiva". De fato, muitas críticas sinalizam 
${ }^{4}$ No original: "The West Wing" is in the middle of something, all right; what it turns out to be is middlebrow".

${ }^{5}$ Em dezembro do mesmo ano, Caryn James reavaliou suas opiniões sobre a série e a qualificou como o melhor e mais absorvente drama da temporada.

${ }^{6}$ Gabriel Spitzer (2001) afirma na resenha Rich are diferent. They Watch West Wing, que a renda familiar média dos telespectadores da série da NBC era de 70 mil dólares, em maio de 2001.
${ }^{7}$ No original: "a president we can all agree on".

\footnotetext{
${ }^{8}$ De acordo com Anna Tous (2010: 140).
}

a função pedagógica da série e seu modo palatável de ensinar política e de fazer entender o interior do complicado sistema partidário americano.

Inicialmente a série parecia ser mais uma daquelas ficções sobre os bastidores do modo de fazer política nos Estados Unidos, construindo um mundo em que o chefe de estado além de ser extremamente humano e democrático, era também um homem inteligente e até premiado com o Nobel em Economia. Enfim, mais um show que tentaria conjugar política com entretenimento a fim de agradar a classe média como a crítica do New York Times, Caryn James (1999, online), afirmou na estreia da série: "The West Wing está no meio de alguma coisa, tudo bem; mas acaba por ser mediana" ${ }^{4}$. Todavia, como estamos trabalhando com um produto seriado, episódico em sua natureza, faz-se necessário um tempo para avaliar as partes como constituintes de um conjunto orgânico que dá forma à ficção 5 .

De fato, os contornos de sua repercussão mudaram e a ficção se converteu num item obrigatório para a audiência americana desde a classe média alta ${ }^{6}$, políticos, intelectuais, analistas e, sobretudo, para a imprensa. Durante o período de exibição (1999-2006), The West Wing foi atravessada por dois governos americanos: o final da administração liberal e recheada de escândalos do presidente Bill Clinton (1993-2001) e os dois mandatos do governo republicano e conservador de George W. Bush (2001-2004 e 2004-2008).

A desmoralização dos democratas e a ascensão dos republicanos levara um vento conservador para a política nos Estados Unidos no momento em que se discutira, por exemplo, projetos ligados aos direitos dos homossexuais, ao aumento de verba para educação e ao combate do terrorismo. Este momento político vai refletir diretamente no modo como seus criadores, sobretudo Sorkin, que era um militante atuante do partido democrata, vão conceber a série e a representação de uma sociedade pragmática e idealista. E certamente este horizonte irá igualmente tecer relações com a própria leitura do seriado feita pela crítica.

Não à toa que um traço recorrente nas críticas foi o de como os criadores da série imprimiram um grau de realismo na narrativa, representado pela exploração de temas recentes da política americana e mundial. Este aparato político "real" desenhado por Sorkin e Schlamme fez despertar na crítica e nos espectadores a pergunta: a Ala Oeste da Casa Branca é assim mesmo? A pergunta não se referia apenas ao dispositivo cenográfico, mas também a uma atmosfera de trabalho ruidosa e acelerada vista em The West Wing. De fato, Sorkin contou com a colaboração de consultores externos (ex-funcionários da Casa Branca) na condução do roteiro que se atualizava constantemente alimentado pelos fatos contemporâneos.

Inevitavelmente a crítica tecia comparações entre os acontecimentos reais e o universo ficcional da série. Elisabeth Clark (2005) aponta que as fronteiras entre ficção e realidade são turvas em The West Wing e afirma ter percebido, em alguns textos, que a crítica tratou a administração de Bartlet (e seu significado político) como se ela realmente existisse fora do território ficcional da TV. Isso se deve, em parte, porque os comentários dos críticos se desenvolveram juntamente com o "real histórico" dos acontecimentos políticos, ocasionando uma espécie de reescrita do fato histórico por meio dos agentes da mídia (CLARK, 2005). Chris Lehmann (2001) da The Atlantic destacou que nas eleições presidenciais de 2000 (que levaram Bush ao poder), o departamento de publicidade da NBC instaurou uma campanha criando a sua versão de candidato a presidente "O presidente que todos nós concordamos"7. Era Jed Bartlet. Ao mesmo tempo na Califórnia começaram a surgir adesivos nos carros com BARTLET FOR PRESIDENT.

A adesão da audiência foi enorme. Durante a sua primeira temporada The West Wing, em certos momentos, chegou a ter 17, 6 milhões de espectadores e mais tarde, oscilando entre 13 e 15 milhões só nos Estados Unidos ${ }^{8}$. Alem disso, o 
próprio Sorkin, ainda durante a primeira temporada, aparecia por vezes no fórum online Television Without Pity (TWoP) para deixar agradecimentos aos fãs. Daniel de Vise (2006) do Washington Post comenta:

${ }^{9}$ No original: “Joel Bradshaw, a computer consultant to a defense contractor had "absolutely no interest in politics, or a show about politics," when he stumbled across a "West Wing" episode early on. The Fairfax resident was hooked by the plot lines, and "it got to the point where I planned my week around not missing an episode of 'West Wing,' " he said. "I've seen people around town with 'Bartlet is my president' T-shirts, and if I knew where to get one, I'd probably buy one." (VISE, 2006 - online).
Joel Bradshaw, um consultor de informática de uma empresa de defesa não tinha "absolutamente nenhum interesse na política, ou num show sobre política", quando se deparou com o episódio piloto de "West Wing". O residente de Fairfax era viciado pelas linhas de enredo, e "chegou a um ponto onde eu planejei minha semana em função de não perder um episódio de 'West Wing'", disse ele. "Eu vi as pessoas ao redor da cidade com camisetas de 'Bartlet é o meu presidente', e se eu soubesse onde conseguir uma, eu provavelmente compraria uma também." (VISE, 2006 - online; tradução nossa) ${ }^{9}$

O roteiro de The West Wing está repleto de referências à "vida real", a ponto do site da série apresentar semanalmente uma página de hot topics com indicadores político-temáticos e ainda questões que os espectadores podiam enviar como informações adicionais. Sorkin atualizava constantemente seu roteiro quase como cópia ressignificada dos fatos reais e sua inequívoca habilidade especular o fez explorar temas diversos da política interna e externa americanas. Vale aqui citar alguns deles ao longo das sete temporadas da série: o drama dos refugiados cubanos; a preocupação com a direita conservadora cristã; as ambições nucleares iranianas e norte-coreanas; as relações tensas entre Índia e Paquistão; ataques de Anthrax contra a administração Bartlet; o financiamento federal para as artes; a questão social ligada aos veteranos de guerra americanos; descriminalização das drogas; pena de morte; restabelecimento da paz e do terrorismo em Israel, Cisjordânia e da Faixa de Gaza; o genocídio em Ruanda e Darfur; Sudão; AIDS na África Subsaariana; assassinatos por crime de ódio, sobretudo à homossexuais; o programa espacial americano; a liberdade de imprensa e finalmente, o emblemático 11 de setembro.

A crítica de Gilberto Silva Jr. publicada na revista Contracampo resume bem a sua avaliação sobre o projeto idealizador da série:

\begin{abstract}
(...) os EUA de The West Wing, mesmo que sujeitos à recorrente ameaça terrorista, não passaram por um 11 de setembro. Sim, a ocorrência do fato, pouco antes do início da 3a temporada, não foi ignorada pelos seus criadores e foi ao ar, abrindo esta temporada, antes do episódio concebido para tal, um especial produzido a toque de caixa - fora da cronologia da série, diga-se de passagem - no qual as personagens conversavam com um grupo de colegiais em visita à Casa Branca sobre um possível "perigo islâmico". Só que o discurso adotado pelo grupo se estabelecia de forma razoavelmente ponderada, tentando manter alguma distância quanto à xenofobia passional na qual o país achavase impregnado. Mesmo atento a essa ameaça, em especial durante a $3^{\underline{a}}$ e $4^{\underline{a}}$ temporadas, os roteiros do programa têm o cuidado de, na maioria dos casos, não generalizar quanto às origens de um terrorismo islâmico, centrando seu foco de ataque à fictícia Qumar e a grupos isolados (SILVA JR, 2011- online).
\end{abstract}

Os ecos da representação de tais temas alimentaram os discursos e as agendas da imprensa e das publicações sobre política, sejam as de política conservadora ou liberal. Parecia que nenhuma esfera estava isenta das discussões provocadas pela série que tornou-se objeto de culto principalmente entre o público de esquerda. Por isso mesmo, algumas vozes da crítica, como a colunista conservadora Naomi Pfefferman do Jewishjournal.com, que rebatizou a ficção de The Left Wing. Por um lado estava a ingenuidade da série ao apresentar uma administração por demais idealizada dos liberais e por outro, a demonização dos conservadores, demonização esta traduzida na composição de personagens com características morais indesejáveis e que não tinham nada a ver com suas convicções políticas. $\mathrm{O}$ apelido ganhou força: 
${ }^{10}$ No original: "The general consensus among fans, insiders and TV critics is that "The West Wing" began as a riff on the Clinton administration. Critics say it continued down that path even as it strayed farther and farther from political reality, to the point that its fictional White House would find liberal resolutions to real-life problems faced by the right-leaning Bush administration. Some Republican detractors dubbed the show "The Left Wing.

11 "As one might expect, Bill Clinton is among The West Wing's biggest fans".

${ }^{12}$ No original: "The West Wing offers an ideal of America. It shows a presidency that acts not only in the best interests of the electorate, but in the best interests of humanity. It's an America that examines its flaws and works to repair them, that invites debate and dissenting opinion while striving to promote a humanitarian agenda. The show works against our cynical preconceptions about real-life politicians, while highlighting the reallife obstacles introduced by the political process. The United States of The West Wing is a world leader not just because of political and military clout, but because of a set of values embodied by a group of highly intelligent and moral civil servants and politicians. Here, the country is "like Mother Teresa with first strike capability," in the words of Communications Director Toby Zeigler (Richard Schiff, I Am Sam)".

13 "Sorkin has an unique style, voice and vision; on almost every show, there's an innovative plot device or a revelatory moment that maximizes the drama of an otherwise dry subject."

${ }^{14}$ Grand Old Party, do partido

Republicano de Bush.
O consenso geral entre os fãs, especialistas e críticos de televisão é que "The West Wing" começou como um solo sobre a administração Clinton. Críticos dizem que continuou por esse caminho ao mesmo tempo em que se desviara, para cada vez mais longe da realidade política, a ponto de sua Casa Branca ficcional encontrar resoluções liberais para problemas concretos enfrentados pela tendência de direita da administração Bush. Alguns detratores republicanos apelidaram o show de "A Asa Esquerda"10 (VISE, 2006 - online; tradução nossa).

A crítica politizou seu relato tal como Sorkin fizera em The West Wing. Com efeito, era quase impossível ficar apartado de um cenário cujos fatos históricos eram marcados por disputas políticas em que era fundamental assumir posições. Entre os diversos textos de caráter mais liberal ou conservador, Lehmann (2001) lembrou que o presidente Bartlet era representado como um líder carismático e hipercompetente como Bill Clinton, mas ao contrário deste (e de J. F. Kennedy) não possuía fraquezas sexuais. Contudo, para o crítico, toda a dignidade moral de Bartlet estava a serviço de uma receita convincente de renascimento do imaginário liberal americano. Lehmann (2001 - online) ainda afirmou que "como se poderia esperar, Bill Clinton está entre os maiores fãs de The West Wing"11 reforçando o que o crítico da The Atlantic chamou de "Clintonismo".

Mas a série, que foi três vezes premiada pela associação americana de críticos de TV, manteve seu prestígio entre a crítica:

The West Wing oferece um ideal da América. Ela mostra uma presidência que atua junto, não apenas, aos melhores interesses do eleitorado, mas aos melhores interesses da humanidade. É uma América que examina os seus defeitos e trabalha para repará-los, que convida o debate e a opinião divergente, enquanto se esforça para promover uma agenda humanitária. O show trabalha contra nossos preconceitos cínicos sobre os políticos reais, salientando os obstáculos da vida real introduzidos pelo processo político. Os Estados Unidos de The West Wing são um líder mundial e não apenas por causa da influência política e militar, mas por causa de um conjunto de valores incorporados por um grupo de funcionários públicos e políticos altamente inteligentes e com princípios morais. Aqui, o país é "como a Madre Teresa, mas com capacidade de antecipação de ataque.", nas palavras do Diretor de Comunicações Toby Ziegler (Richard Schiff, I Am Sam) (WILD, 2005 - online; tradução nossa). ${ }^{12}$

A quase unanimidade da crítica reconhece o imenso talento de Sorkin como roteirista, Heather Havrilesky (2003 - online), crítico de televisão do Salon.com, afirma que "Sorkin tem estilo, voz e visão únicos; em quase todos os shows, há um enredo inovador ou um momento revelador que maximiza o drama de outra forma" ${ }^{\prime 13}$. A sua perícia na construção de personagens extremamente morais e na elaboração dos diálogos que equilibram doses de drama e humor, foram reconhecidos pela crítica que destinou o mérito da série quase que exclusivamente à habilidade do roteirista e à excelência do elenco.

Por isso, quando Sorkin e Schlamme retiram-se da produção motivados por um desgaste interno na emissora, no final da quarta temporada (2003), e o controle total passa para as mãos do produtor John Wells, a crítica (e também os fãs) avalia o fato como uma mudança no tom político da narrativa que "faz as pazes com G.O.P. ${ }^{14 "}$ e aproxima-se mais do "centro" segundo o texto de Bill Carter (2003 - online) do The New York Times. A série ainda permaneceu por mais três temporadas e, embora mantendo certo padrão de qualidade nos diálogos, já não despertava tanta polêmica como antes. 


\section{Considerações finais}

Apesar de encerrada sua última temporada em 2006, The West Wing ainda é apontada como uma espécie de moeda cultural entre críticos, fãs e intelectuais. Em 2010, fãs "die-hard" criaram contas no twitter e assumiram a identidade de alguns dos personagens principais da série como a do presidente Bartlet, a de Josh e a de Leo. O interessante é que estas contas misturam a ficção com fatos do mundo real, similar a experiência de leitura da crítica. O verbete The West Wing na Wikipédia agrega inúmeras informações e fontes que impressionam não só pela quantidade, mas sobretudo pelo destaque dado à série. Prova disso são os links para 60 publicações (em setembro de 2012) e a ênfase dos tópicos reações da crítica e impactos sociais.

Por sua dimensão e alcance, The West Wing foi recebida e lida no espaço do jogo de mediações no qual as críticas jornalísticas, ao lado de outras instituições de pressão social, se inserem. A crítica legitimou e ajudou a validar a série não apenas para a emissora, mas sobretudo para o público. A chancela de TV de qualidade ou mais recentemente de Art TV concedida à ficção reforça os atributos da narrativa.

Atravessando um panorama em que as questões políticas eram vistas com uma familiar monotonia e certa dose de descrédito, a crítica suscitada pela série não se omitiu da partidarização de seu relato, seguiu as "instruções contextuais" e se conformou enquanto prática receptiva. E, embora deixando de lado a suposta objetividade do distanciamento crítico para assumir posições, sejam liberais ou conservadoras, as avaliações sobre The West Wing confirmaram o êxito da série. Mas por que a crítica deu pouca relevância aos aspectos estéticos do seriado? Arriscamos dizer que as estratégias contextuais guiaram o discurso da crítica que, contaminada pela grande repercussão política da série e por um grau intencional de realismo previsto no roteiro, destinou pouco tempo para compreender, por exemplo, a complexidade narrativa de The West Wing. Jason Mittell observa que frequentemente os episódios de The West Wing iniciam "com uma chamada a partir do clímax da história e então voltam o relógio para explicar a situação confusa com que o episódio começou" (2012: 47). Esta carência de instruções iniciais explícitas pode provocar desorientações no espectador comum, mas ao mesmo tempo, o incita a assumir um papel ativo na compreensão de uma história complexamente narrada. Mittell conclui que as complexas estratégias de narração estão fortemente presentes hoje em "contextos expressamente populares para uma audiência massiva" (2012: 47). Além disso, o emprego constante do plano sequência e a tática do Walk and Talk, para ficarmos apenas nos elementos mais aparentes, foram insuficientemente explorados pela crítica a The West Wing.

Evidentemente que podemos invocar outras causas para a desimportância dada ao exame dos elementos formais da série, como a falta de perícia de muitos críticos em lidar com narrativas seriadas ou mesmo a carência de espaço para análise nas publicações. Porém, julgamos que condições contextuais específicas de produção e recepção, influenciaram a resposta da crítica.

Resta-nos referir que nossa proposta faz parte de uma pesquisa ainda em curso e que partiu de um universo consideravelmente grande de críticas e de textos bem heterogêneos. Ainda assim, pudemos verificar um quase consenso redacional no que diz respeito à The West Wing, ou seja, as suas qualidades estavam necessariamente vinculadas ao modo como seus criadores, particularmente, Aaron Sorkin, despertara a fé pública pelo debate político. Esperamos que esta fé se mantenha por muito tempo. 


\section{Referências Bibliográficas}

CARTER, Bill. The West Wing' Comes to Terms With the G.O.P. New York Times, 23 Set. 2003.

CLARK, J. Elisabeth. The Bartlet administration and contemporary populism in NBC's The West Wing. In: HAMMOND, Michael: MAZDON, Lucy. The contemporary television series. Edinburgh: Edinburgh University Press, 2005, p. 224-243.

GOMES, Regina. The West Wing: análise dos recursos estéticos do episódio piloto. In: Televisão: formas audiovisuais de ficção e documentário. Faro e São Paulo, 2011.

HAVRILESKY, Heather. Will the west wing go south? (2003). Disponível em: <http:// www.salon.com/2003/05/14/west_wing_5/>. Acesso: jan. de 2010.

ISER, Wolfgang. A interação do texto com o leitor. In: LIMA, Luiz Costa. A literatura e o leitor: textos de estética da recepção. Rio de Janeiro: Paz e Terra, 1979.

JAUSS, Hans Robert. A história da literatura como provocação à teoria literária. São Paulo: Ática, 1994.

. Pequena apologia de la experiência estética. Barcelona: Paidós, 2002.

. Estética da recepção: colocações gerais. In: LIMA, Luiz Costa. A literatura e o leitor: textos de estética da recepção. Rio de Janeiro: Paz e Terra, 1979.

LEHMANN, Chris. The Feel Good Presidency: the pseudo-politics of The West Wing, 2001. Disponível em: <http://www.theatlantic.com/magazine/archive/2001/03/ the-feel-good-presidency/302138/>. Acesso: jan. 2010.

MITTELL, Jason. Complexidade narrativa na televisão americana contemporânea. In: Revista Matrizes, São Paulo, ano 5, n. 2, jan/jun, 2012, p. 29-52.

PFEFFERMAN, Naomi. The Left Wing, 2001. Disponível em: <http://www. jewishjournal.com/up_front/article/the_left_wing_20011012>. Acesso: jan. de 2010.

ROLLINS, Peter C.; O'CONNOR, Jonh E. eds.. The West Wing: the American presidency as television drama. New York: Syracuse University Press, 2003.

SILVA JR, Gilberto. The West Wing: nos bastidores do poder. Disponível em: <http:// www.contracampo.com.br/69/thewestwing.htm>. Acesso: out. de 2009.

SPITZER, Gabriel. Rich are different. They watch 'West Wing.'. Disponível em: <http://www.medialifemagazine.com:8080/news2001/may01/may14/1_mon/ news2monday.html>. Acesso: fev. de 2010.

STAIGER, Janet. Interpreting films: studies in the historical reception of american cinema. Princeton: Princeton University Press, 1992. Press, 2000

Perverse spectators: the practices of film reception. N.Y: New York University . Media Reception Studies. N.Y: New York University Press, 2005.

TOUS, Anna. La era del drama en televisión. Barcelona: Editorial UOC, 2010.

VISE, Daniel de. City Says Goodbye to 'West Wing,' Its Chattier Self. Washington Post,15 mai. 2006. Disponível em: <http://www.washingtonpost.com/wpsrv/metro/ daily/051506/westwing.html>. Acesso: jan. de 2010

WILD, Diane. The West wing: The complete fourth season. 2005. Disponível em: <http://www.dvdverdict.com/printer/westwingseason4.php>. Acesso: fev. de 2010. 